\title{
THE ROLE OF REASONS AND SENTIMENTS IN TUGENDHAT'S MORAL PHILOSOPHY
}

\author{
Adriano NaVEs de BRITo \\ Department of Philosophy \\ Unisinos University \\ brito@unisinos.br
}

SUMMARY: In this paper I discuss Tugendhat's moral philosophy by focusing on his conception of moral justification and the role sentiments play in it. In order to understand, and to criticize, the relationship between reasons and sentiments in Tugendhat's moral philosophy, the correlation between judgment and affection is scrutinized. Furthermore, I argue that as far as the innermost structure of morality is concerned individuals have far less autonomy to accept or reject any moral system than Tugendhat is prepared to admit.

KEY WORDS: autonomy, structure of morality, moral justification, moral sentiments

RESUMEn: En este artículo discuto la filosofía moral de Tugendhat mediante la investigación de su concepción de justificación moral y del papel que los sentimientos desempeñan en ella. Para comprender y criticar la relación entre razones y sentimientos en la filosofía moral de Tugendhat, analizo la correlación entre juicio y afecto. Sostengo, además, que, en lo que atañe a la estructura más básica de la moralidad, los individuos tienen mucho menos autonomía para aceptar o rechazar un sistema moral de lo que Tugendhat está dispuesto a admitir.

PALABRAS CLAVE: autonomía, estructura de la moral, justificación moral, sentimientos morales

\section{Introduction}

Tugendhat's criticism of Kant's grounds for moral obligation is well known (cf. e.g. Tugendhat 1993, chapters 6 and 7). The idea of an absolute Reason as the basis upon which morality has to be built has no descriptive force for him. The problem he sees here is not that Reason (with a capital ' $R$ ') is not a basis on which to plant the seeds of morality. This would only be possible if this "Reason" existed, but it does not. However, Tugendhat considers that morality among human beings requires justification. Since there can be no complete phenomenological description of a human group without including a description of the rules through which the behaviour of this group is reciprocally evaluated and constrained, moral obligation must somehow be justified. Otherwise, he asks, how is it possible to explain that human beings submit themselves to moral limitations rather than not doing so? Thus Tugendhat's guiding question concerning morality is 
how moral obligations are to be justified, since this is necessary if they are to be obeyed.

Tugendhat's conception of morality is largely based on the role sentiments, particularly indignation, guilt and shame, play in it. ${ }^{1}$ In his view, moral sentiments are fundamental elements in our moral constitution, without which conscience and obligation and the like cannot be explained in a way that would be consistent with both an enlightened view of man and the refusal of Reason in a Kantian sense. Yet if justification is what needs to be explained, moral sentiments ought to help us understand why human beings prefer to accept moral constraints.

It is important to note from the outset that the descriptive strength of Tugendhat's approach to morality strikes me as highly convincing. The idea of taking as a starting point a concept of morality based on a phenomenological description of how human groups live together restrains the normative impetus to which moral philosophers are prone when dealing with this issue. At the same time, this idea acts as a guide in the investigation, helping to determine how things really work within the realm of morality, and may provide us with a genuine understanding of its human structure.

Nonetheless, and despite my enthusiasm for Tugendhat's achievements in describing the structure of morality, I am less happy with the emphasis he places on the issue of justification. I will now state briefly my critical view on the matter, as I shall return to this point in more detail later. Tugendhat's concern is with the justification of moral judgments. Contrary to empirical judgments, whose claims for objectivity rest on empirical facts, moral judgments cannot rely on facts in order to have their claims for objective validity granted. Nonetheless, moral judgments do raise such claims, as is clear in the case of judgments expressing obligations. What interests Tugendhat is understanding the legitimising basis for these claims. Since he does not believe in absolute grounds for moral obligation, be it in a Kantian or a religious sense, his view dictates that what should be justified is not that it is good (in an absolute sense) to follow a certain course of action, but that it is plausibly better (cf. Tugendhat 1993, chapter 5) to follow one course rather than another. Justification, in this sense, must deal with some determination of choice. Hence, to justify is to give reasons for choosing $A$ instead of $B$, or, in a different formulation, to answer why an individual should make a

\footnotetext{
${ }^{1}$ These are the type of sentiments which are implicated in accepting a moral system, or belonging to a moral community.
} 
specific choice from among multiple possibilities. Here a particular criterion is required. Thus if we consider that Tugendhat's discussion involves at the highest level whole conceptions of morality, ${ }^{2}$ then, at the end of the justification chain, a criterion for choosing one among several different moral conceptions is required. That such a criterion might be provided is, however, denied by Tugendhat. So the result would appear to be inconsistent with the picture he ultimately presents of the system of morality. In fact, it is apparently inconsistent with his thought, because if one chooses to emphasise the need for justification, one will be bound to search for a criterion which is in essence the same as that promised by the kantian and religious positions: namely, an objective criterion for this fundamental moral choice - one that would need to be more than the mere individual's will. ${ }^{3}$

It is my opinion that Tugendhat's investigation was vitiated in part by the issue of justification, and I believe that this was due to his feeling called upon to offer an alternative to the individualistic tradition of the Enlightenment, which overestimated the individual's capacity for choice, as well as the need for a basis in morality. In order to counter the morality of the Enlightenment, Tugendhat remained within its conceptual premise (cf. e.g. Tugendhat 2006). At any rate, he may either attempt to describe the system of morality - and the result he obtains is that there can be no absolute value, and therefore no ultimate justification, for choosing one conception of morality over another-, or he may attempt to justify a minimal conception of morality, in this case universalistic and egalitarian. Both procedures are not compatible tout court with Tugendhat's research procedures, although a description of the structure of morality may itself prove compatible with universalism and egalitarianism.

I once confronted Tugendhat with some of these criticisms. He pointed out to me that I might have mistaken the very aim of his philosophical endeavour, which was to better understand morality. In

2 "[To live in symmetry with others] is not some ideal, but we stand here in front of a bifurcation concerning the principles according to which one wants to understand oneself in his relationship with others: either in a way in which one considers others' interests, or in a way in which one exploits the possibility of his own advantage: morality or power. The same moral bifurcation - between exploiting one's advantages or taking the others in account- repeats itself in the question: 'how do we want to understand morality?" (Tugendhat 2001c, p. 182). (All translations of Tugendhat's texts in this paper are mine.)

3 "To the question: "why should we see morality this way?" we cannot answer: 'because the concept of morality demands symmetry'; we can only answer: 'if we want symmetry, we have to see it this way" "(Tugendhat 2001c, p. 182). 
truth, he was not seeking to offer a justification of any kind, but was merely trying to understand what can be found in moral justification or, in other words, how we can understand this when we consider that moral judgments require de facto justification. He was therefore neither interested in discussing the need for the moral justification we actually give, nor in providing himself with a justification, but rather in understanding its structure.

I believe Tugendhat achieved what he intended, i.e. to better understand the structure of morality, although he did more than that. Therefore I still think there is something odd about the role justification plays in Tugendhat's moral approach, and I also think that this oddness is somehow related to the balance his view establishes between reason and sentiment on describing the structure of morality among human beings. This description is what he meant to give, and deserves to be better clarified by separating it from the issue of justification.

Nonetheless, I am aware that things are much more complicated than they have been presented so far. In this paper, I want to investigate the system of morality, rather than to emphasise justification. However, I also want to do so through a discussion of Tugendhat's moral philosophy. Thus an analysis of "justification" as Tugendhat uses it, is inevitable, since he seeks for a clarification of the system of morality by means of explaining moral justification (cf. Tugendhat 2001b). My task will be, therefore, to explain as clearly as possible the sense Tugendhat gives to moral justification, along with the exposition of his view on the structure of morality. I will also attempt to depict the system of morality by striking a balance - or should I say an imbalance - between reason and sentiment which is different from that defended by Tugendhat.

\section{Morality and Moral Justification}

More than once, Tugendhat has claimed that his approach to morality has an advantage over others: he starts with a clear definition of morality (cf. e.g. Tugendhat 2001b, p. 92, and 2001c, p. 169). A general and concise formulation of his definition would be, as he puts it in the preface of the Aufsätze (Tugendhat 200la, p. 7): A morality is a system of reciprocal demands. It is worth noticing that a place for justification is not implicitly provided in this plain definition. Tugendhat, however, gives a more complete formulation which entails many "correlated aspects", including justification: 
Morality, in that sense, is a system of reciprocal demands, which are expressed in have-to clauses. The 'have-to', the duty, is supported by the affections indignation and guilt. To each system of that kind belongs a concept of a morally good person. Because this type of normative system limits its members' freedom, individuals must see it as justified - for them as well as for the other members - and they enter the system only because they accept it as justified. (Tugendhat 2001c, p. 164)

The role played by justification in the system of morality is now clearly established in Tugendhat's conception and is fundamental. Without justification there can be no moral system, since no individual would subject himself to the demands of others by giving up part of his freedom unless he saw those demands as justified. Without justification, therefore, there would be no moral system at all, because there would be no membership of that system. Since there are de facto moral systems, they must be accepted as justified by their members.

As regards the above definition, in order to clarify how justification is to be understood, we need first to clarify under what conditions an individual would consider a moral system justified, so that he would submit himself to its norms. The correlations between the elements in Tugendhat's definition of morality may provide us with an answer. In every moral system there is a concept of what it means to be a "good person", and individuals will take part in this system if they accept this concept as their own, that is, if they assume that the person as described in the concept is the person they want to be. The fact that they do accept the concept as their own is clear if, for instance, they feel ashamed of themselves for not living up to it. So unless they live up to the concept, they will despise themselves, and this is what it means for them to see the concept as justified. In short, a moral system is justified for individuals — or they are willing to submit themselves to its norms - if they accept the concept of a good person which accompanies it as justified. This is defined by their readiness to react to a breach of the norm, whether committed by themselves or by others with moral sentiments, with e.g. indignation, guilt or shame.

What is crucial here is the postulated correlation between the reasons one needs in order to consider a system of morality justified, and the sentiments which provide a criterion for determining whether a moral system is accepted or not as justified by individuals. The relationship between reason and sentiment opens an important door 
to the structure of morality. In order to understand this relationship, it is essential to understand better the correlation between judgment and affections. In this connection, Tugendhat follows the ancient tradition of Aristotle. Affections must be backed by value judgments, otherwise they would be senseless. ${ }^{4}$

Does this explanation entail that having moral sentiments depends on having justifications for them? Is the relation established by Aristotle one between justification and sentiments, or just between value judgments and their corresponding sentiments? It seems to be evident that one evaluates something as bad because one thinks it is bad, or one acknowledges it as bad, but the fact that the thing evaluated is considered bad obviously does not follow from one's considering it as so, rather it follows from one disliking it. How can one judge something considering its value, if not by relating it to what one appreciates or not? In this sense, value judgments are judgments of the way we feel about things. The Aristotelian tradition is then right in asserting that there must be a correlation between one's value judgments and one's feelings, and vice versa. This tradition says, however, nothing about what comes first in the relationship. Hence, there is indeed a fundamental connection between value judgment and affections, and it is a connection of mutual dependence. It is, therefore, a symmetrical connection.

Tugendhat, however, gives a definition of moral sentiments which makes them dependent on moral judgments. I quote: "Moral affections are, however, defined in terms of unpleasant feelings, which are feelings based on judgments about moral disadvantages" (Tugendhat 1993, p. 20). Following this definition, one cannot call the affections one has "moral sentiments" unless these affections are based on moral judgments. In Tugendhat's words: "[moral] affections vanish if we no longer judge morally. We have no reason to be outraged by or to have ill feelings towards someone's action, and we would not even understand those affections, were we not to judge his action as bad" (Tugendhat 1993, p. 20).

Let us now return to justification. How does the concept used in Tugendhat's definition of morality fit with the Aristotelian view on value judgments and their related affections? One part fits the

4 "For all affections what Aristotle clearly showed and established (Rhetoric, Book 2) remains valid for the whole philosophical tradition: viz, that what we call affections are always positive or negative feelings (pleasure or unpleasure), and those feelings make sense because they are based on judgments, value judgments in fact" (Tugendhat 1993, p. 20). 
explanation perfectly well, but the other does not fit at all. If "justification" is tantamount to "judgment", there is an obvious mutual dependence between accepting a system of morality as justified, and reacting to it by means of moral sentiments. In this sense, to accept a moral system as justified means nothing more than to judge it as good, which is the same as stating that one appreciates the moral content of the system in such a way that one is ready to react affectively against it, be it with indignation, guilt or shame. Thus, in this sense, to justify a system is to judge it, which, as far as morality is concerned, causes one to react affectively to it. Here, everything is perfectly correlated. Nevertheless, if this is so, how is justification to be understood as a conditio sine qua non for an individual to enter a moral system, as Tugendhat claims at the end of his definition of morality? How can a symmetrical relationship come to establish an asymmetrical condition?

I think that another meaning of "to justify" is present in the last part of Tugendhat's definition. A meaning that implies his definition of moral sentiments. Since moral sentiments, as he defined them, rely on moral judgments, the individual has to accept these judgments as justified in order to have the corresponding moral sentiments. Only if he has these sentiments, is he ready to enter a specific moral system. The relationship between judgment and affection is here not symmetrical, since, as Tugendhat states the matter concerning morality, moral sentiments depend on moral judgments which require justification. "Justifying" is no longer used in the sense of "judging", but in the sense of "giving reasons for", as when one has the chance to decide to do something or to act in a way one is not yet committed to, or in the sense that one needs reasons to accept a judgment as valid. This is precisely the sense in which we use it relative to our thoughts about, for example, entering into agreements or participating in games.

What I want to show next is that "justification" in this sense does not belong to the innermost structure of morality, although it belongs to certain networks of human relationships, namely, those which Tugendhat himself refers to as quasi-moral, and in which the strength of moral sentiments is diminished.

\section{The System of Morality}

It is important at this point to clarify how the term "morality" is used. The challenge for Tugendhat's definition of the word "morality" (cf. Tugendhat 2001c, pp. 163-166) is to keep it open enough to 
accommodate different conceptions (even antagonistic conceptions) of morality, so that ultimately it does not sound absurd to talk about "morality" as a general concept. ${ }^{5}$ Only if we agreed to use "morality" to refer to the innermost structure of human morals, rather than to a particular moral system, would the challenge have to be faced. So I think this is the sense that best fits Tugendhat's prima facie use of the word in his definition, and it refers to a broad and basic phenomenon, which still needs to be better understood. Hereafter, I will call it "the first order morality".

Now, it is interesting to adopt a negative perspective on the case for justification, and ask, "what if the individual did not consider a system of morality to be justified?" According to Tugendhat's definition of morality, he would not subject himself to it. And what about his moral affections? Would his remaining outside the system prevent him from having affections towards others or prevent others from having affections towards him? I believe it would not. He would simply feel no constraint in accepting indignation from individuals who belong to the system he has rejected and, consequently, he would not be made to feel ashamed ${ }^{6}$ by their rebuke. Nonetheless, he would judge the system and its participants just as much as they would judge him. Thus the judgment of both parties would be subject to the corresponding affection. Remaining outside a particular system of morality does not mean to leave the whole system of reciprocal demands, which defines the first order morality.

Let us suppose that an individual sees the Mullahs' moral system as not justified. He would not feel ashamed at not living by its stringent rules. Nevertheless, this would not prevent him from being morally angry about, for example, the way women are treated under the Mullahs' regime. Their rules governing the behaviour of women could then arouse his indignation. On the other hand, the Mullahs' followers could feel indignant at his way of life, while they would not feel ashamed at the same individual's criticism of their moral principles. There is here a peculiar asymmetry, which I think is essential

5 "As soon as Morality is not justified in an authoritarian way, we can talk about Morality [in general], and not about a morality, and then we are liable to understand it in universalistic terms" (Tugendhat 2001c, p. 168).

${ }^{6}$ In the sense that shame and guilt are affections that an individual has because he considers he has acted in a bad way, they are equivalent moral sentiments. Here I follow Tugendhat: "we feel indignation when we react affectively in a negative way to someone's action because we consider it a bad action; resentment when an action which I judge as bad harms me; and guilt or a certain form of shame in view of an action of mine which I consider bad". (Tugendhat 1993, p. 20) 
to the innermost structure of morality as a unified system of reciprocal demands. While indignation recognizes no boundaries between particular moral systems, shame and other moral sentiments do.

An important outcome of the above thoughts concerning the distinction between particular moral systems, and morality as a broad system of reciprocal demands, is that there is a corresponding asymmetry between indignation and shame (or guilt). Yet the conditions required for taking part in these two levels of moral system are different. Let us now, for the sake of clarity, call any specific system of morality, which depends on the requirements of the first order morality, a "second order" morality. To belong to the first order morality, its members are required merely to be capable of having moral sentiments. Here the basis for indignation and shame or guilt need not be the same among all members, but all members must be able to show those sentiments. This characteristic is precisely what neither nonhumans nor psychopaths (who lack moral sense) can demonstrate. They do not, therefore, belong to the network of human morality unless they are represented in it by authorized members (e.g. societies for the defence of animal or human rights). It is important to note that at this level, contrary to the position defended by Tugendhat, moral judgments have no precedence over moral sentiments. On the other hand, being part of the second order morality requires the individual to share with other members the same basis for having equivalent moral sentiments. Every human being (with the exception noted above) belongs to the first order morality for life whether he wishes to or not, and only in that sense does humanity constitute a unique moral community. Everybody can provoke or become the object of the indignation of others. In addition, we all belong to some system of reciprocal demands of the second order morality. Nonetheless, systems of morality at the second order level consist of a vast mosaic of moral communities, with more or less overlapping agreements at their borders. Within the mosaic we can move with relative freedom.

As far as first order morality is concerned, it obviously makes less sense to talk about autonomy or heteronomy, since for those individuals capable of having moral sentiments there is almost no choice but to submit themselves to reciprocal demands. As regards the mosaic of second order morality, because of the huge varieties of bonds that link communities, autonomy and heteronomy assume highly variable values, from a nearly total absence of autonomy (as in one's family) to almost full autonomy (as in a market). 
I cannot go much further in explaining the phenomenology of second order moral systems, but I do not need to go much deeper in order to draw some partial, though important, conclusions about the problem of justification we began with. Let us return to Tugendhat's moral definition. With respect to justification in the sense of given reasons, and because of the way he understands moral sentiments, his definition crosses the line between the two orders of morality. He begins by discussing morality as a system of reciprocal demands, that is, morality as a system in which every individual participates, regardless of their circumstances and judgments, and in respect to which it makes no sense to ask for reasons for belonging to the system, but then goes on to discuss systems of morality about which it does make sense to ask for reasons for belonging. He describes the fundamental structure of morality, and ends by trying to answer the normative question of which particular morality it is more plausible for the individual to belong to autonomously. This is precisely the way in which the foundational tradition of the Enlightenment faces the moral problem.

Tugendhat's approach puts the descriptive gain of his definition at risk because while he oversimplifies how things work at the second order level, he overlooks the asymmetric correlation between indignation and shame or guilt which characterizes the first order level, and which shows that these sentiments can appear independently of a justification (in the sense of "given reasons for") of their correlated judgments. Even when they are dealing with second order morals, individuals are hardly, if ever, faced with the clear choice of accepting by reasons a particular system or not. Most commonly, the individual's alternative is rather to allow himself to be excluded or not from the system, because he is already part of it, and normally bound to it by strong feelings. It may seem that I am taking away the autonomy of choice from the individual, but I am not. What I am trying to show is that if we insist on the picture of a detached individual making his moral choices through reasoning before entering the moral system, we will not be able to understand how the autonomy he has is in fact rendered effective in making moral decisions. To understand this phenomenon we need to know how moral sentiments work in the inner networks of morality. Even though it may seem paradoxical, the issue of justification can help us once again. 


\section{Autonomy and Heteronomy in Morality}

If an individual considers a particular system of morality justified, he will then accept its corresponding demands autonomously, i.e. he may then say, "I accept these demands because I wish to". But if one asks him why, his answer may be, for instance, "Because it is rational", or "Because it is good for me", or "Because it is the best for all concerned", or even "Because it is God's will". Whatever he may respond, his answer will refer to a motive which is related to a certain moral content to which he attributes a value, e.g. rationality, cooperation, religiosity. With all these answers, one may always pose the why-question in such a way that it would be pointless to repeat it. The question would then be, "Why do you want to act morally?" and, in line with the initial argument concerning levels of morality, "Why do you want to belong to the human moral community?" The first of the above questions belongs to the scope of what I have called "second order morality", but the second one belongs to the scope of first order morality, and the answer to this question reveals a fundamental characteristic of human beings and, therefore, a fundamental characteristic of their moral structure. In fact, an individual may choose, within certain limits, between acting rationally or acting religiously, but can he choose between belonging or not belonging to the human moral community? I agree with Tugendhat that there cannot be any further moral justification beyond the ultimate "I want this to be", or "I want symmetrical relationships" (cf. Tugendhat 2001c, p. 182, quoted above). However, can an individual decide not to want to be part of the human moral community? In line with the definition given of the first order morality, he would have to be able to control his feelings up to the point of ceasing to have moral sentiments. He would have to be able to decide, without experiencing any feelings of shame or guilt, to become devoid of moral sense. No one can achieve this autonomously, but only after doing so would he step outside the human moral community. Indeed, he would then be excluded from it. What individuals ultimately want is to continue taking part in the human community, which implies that they want to continue taking part in a particular system of reciprocal demands, which coexists within the inner networks of morality. How free an individual is to accept a particular system of morality or not depends on our condition as social beings and on the system in question. If this is the family he was born into, his autonomy is very limited. But if it is an agreement, his autonomy may be much wider. In other words, the question of which particular moral community he will 
accept is, within certain limits, a matter of choice for him, but the fact that he ultimately wants to continue being part of a community is not. This fact corresponds to our fundamental condition of having moral sentiments, and, symmetrically, the judgments related to them. This means that we all belong to the human moral community, and, therefore, that we are all exposed, no matter what, to reciprocal moral approval or disapproval.

Tugendhat's recurrent example of the relationship between the child and her parents reveals quite clearly how the fundamental structure of morality determines the multiple systems in the moral mosaic. After the parents have exhausted their justifications for the child to act according to the rules of a particular morality, they reach the point where the child's question is simply "Why should I act morally?" At that stage, there is no further recourse beyond the child's own will. The parents must ask the child what she wants. We already know the child cannot decide to step outside the whole system of reciprocal demands, or reciprocal indignation, so that the ultimate question for the child is whether she wants to continue being part of the community she is already part of, or whether she wants to face the indignation of others. The child will finally be asked, "Do you want to continue to be considered a member of this family? If so, you have to endorse our values."

This example is good because it shows the narrow limits within which human moral autonomy is shaped. It is ultimately up to the individual to say "yes" or "no" to the particular system of morality he is committed to, but we understand that this does not mean prima facie to say "yes" or "no" to the content of the norms, but to say "yes" or "no" when asked whether he wants to continue being a part of the community or not, and this is a deeply affective question. To state that this depends on the individual is to state, pace Tugendhat, that to resort to an individual's will is ultimately unavoidable. However, what he has to decide at this level is not to enter a system he is already in, but not to be excluded from it. The decision here must be taken ultimately on the basis of his moral sentiments and their correlated judgments, since this is what defines his belonging to the community. He cannot, therefore, step outside his own sentiments to ask whether the system is worthwhile for him or not. He cannot step outside his own moral sentiments to ask for reasons for having them. The individual does not want to be despised, i.e. he cares about what the other members of the community he is questioning think about him; he cares about being liked, so he still feels bound to the system. The individual may, 
of course, step outside a particular morality, but this means that he must stop feeling ashamed or guilty of acting against its norms. How deeply involved humans are with the different moral systems they live in can be shown by psychology in the way it describes the development of the personal identity of human beings.

All things considered, the final recourse to an individual's will is not made in a positive sense, but in a negative one. What the child must decide is not if she wants to live within the system of reciprocal demands, which defines the first order morality, and to which she belongs whether she wishes to be or not, nor if she wants to enter a particular system in the moral mosaic or not. What the child has to decide is whether or not she will be excluded from the community she is already accepted as belonging to, or indeed if she can stand being excluded from it. By taking this for granted, it becomes clear that an individual's ultimate decision to allow himself to be excluded or not from a particular system of morality which does not distance itself too much from the core of morality does not concern prima facie its content, and hence, judgments which require to be justified by reasons. This content may be contractual, rational or religious, but is primarily related to the human need to be part of a community, the need to be accepted. All this reflects a remarkable and fundamental characteristic of human moral structure, namely, that morality depends first and foremost on binding moral sentiments, and not on reasons.

Reasons, in the sense of justifications to endorse a system, grow in importance as we move away from the core of morality, where sentiments are vital, to its edges, where sentimental ties are looser. The nearer individuals are to the affective core of morality (where, as I have already pointed out, it hardly makes sense to talk about autonomy) the less autonomy they have to decide in accordance with rational motives. And the farther they are from the core, the more autonomy they enjoy to do this. Justification, in the sense of having grounds for accepting a system of morality, follows the same pattern. Nevertheless, as Tugendhat has shown, when moral sentiments are absent, so is moral consciousness, and one can only speak of a quasimorality.

The above analysis, though very close to Tugendhat's, makes a change that is, in my view, crucial for an accurate comprehension of the structure of morality. After climbing the ladder of moral sentiments to a general concept of morality, we cannot ignore it by showing individuals as affectively autonomous beings who demand 
reasons in order to accept moral constraints. On the contrary, individuals are indelibly bound to reciprocal demands based on moral affections and their corresponding value judgments. Without this change of perspective, the emphasis on justification tends to override the importance of reasons in moral decisions. When matters are described in this way, it is difficult to avoid contractualism, be it in its classical form or in Tugendhat's symmetrical form, as the only enlightened concept of morality which is compatible with an individual's autonomy and, therefore, with contemporary pluralistic society. That, I think, is why Tugendhat has always tried to make sense of contractualism in his moral philosophy.

Of course, one may be interested in investigating how individuals would — or should - act in situations where they have the kind of autonomy they do not have in morality. This is, for example, very useful in economics or politics, where power struggles are examples of this kind of system. They are, however, not moral systems in the sense I have, pace Tugendhat, defined in this paper. One may object that this is just one ad hoc definition among many, which is true. The most important aspect to consider, however, is not the definition itself, but the issue for which one is interested in having a theory: either human choice in contexts which are relatively free from affective constraints, or the innermost structure of the reciprocal affective demands we are all subject to. The former presupposes a common ground where contracts can be agreed, whilst the latter is the ground upon which any agreement can be made. Both are useful theories about important issues concerning human life. As I see it, Tugendhat's approach to morality must be seen as an attempt to shed light on the structure of morality. It is in this sense that I think it deserves to be analysed.

\section{Some Concluding Remarks}

It is worth taking note of some outcomes of the above analysis of Tugendhat's moral philosophy. Firstly, that justification may be a red herring, since it may lead one to inadvertently fuse different spectrums of morality - morality as an agreement (cf. Gauthier 1986) and morality as a system of reciprocal demands. For this reason, we may put at risk both an accurate description of the structure of morality, and a defence of a particular concept of morality. Secondly, the normative approach to morality is certainly an urgent philosophical task. To go through the mosaic where morals converge, as is inevitable in a highly interactive society like the one we live in, we need rules which 
can only be arrived at through a discussion of reasons each side may have to agree to. Notwithstanding this fact, it is also an extremely important philosophical task to understand what the moral basis on which any agreement might be reached would actually look like. Tugendhat's moral philosophy makes an invaluable contribution, as I see it, in that it gives an accurate description of the innermost moral structure of human beings. Finally, I would like to draw attention to at least one amendment one should add to his description. This is the recognition of the asymmetry between indignation and shame or guilt, which is fundamental to morality as a system of reciprocal demands, but which does not characterise specific morals based on agreements.

These outcomes are compatible both with our common intuition concerning moral values, and with what science has discovered about human development from its most primitive stages onwards. I regard these as relevant criteria - though not the only ones - to evaluate a philosophical thesis. At any rate, it is interesting to submit to scientific scrutiny the premise that human beings do not demand benefits in order to enter a community, but that life in a community is rather a benefit in itself, since it is an essential condition for human existence. It is to keep that benefit available that morality, as a system of reciprocal demands sustained by affective predisposition, is indispensable. After all, the interest in, and the necessity of, belonging to a social group are the invisible forces that keep our moral compass pointing in the right direction. ${ }^{7}$

\section{REFERENCES}

Gauthier, D., 1986, Morals by Agreement, Oxford University Press, Oxford. Tugendhat, E., 2006, "Das Problem einer Aufgeklärten Moral", in N. Sacaro and M. Suárez, 2006, Ernst Tugendhats Ethik: Einwände und Erwiderungen, Beck, Munich, pp. 14-30.

—_. 200la, Aufsätze 1992-2000, Suhrkamp, Frankfurt am Main. -, 2001b, "Was heißt es moralische Urteile zu begründen", in Tugendhat 2001a, pp. 91-108.

__ 2001c, "Wie sollen wir Moral verstehen?", in Tugendhat 2001a, pp. 163-184.

—_, 1993, Vorlesungen über Ethik, Suhrkamp, Frankfurt am Main.

Received: July 30, 2007; revised: July 11, 2008; accepted: July 28, 2008.

${ }^{7}$ This paper was written thanks to the financial support of the Brazilian National Research Fund (CNPq) to which I am deeply grateful. 